\title{
Issues of Participatory Digital Theatre. \\ Reflections on Three Forms Developed during the Pandemic
}

\author{
Eliane Beaufils \\ elianebeaufils@aol.com
}

This article studies three participatory theatre-forms on zoom. It aims at analyzing what kind of participation is possible in the space of video-conferencing, which is both located in a private room and at a distance. These theatres seem able to interpellate the audience on a cognitive as well as a social and even an affective level. Each apparatus focuses on a different dimension, be it imagination, empathy or criticality. Yet the interactions result in an experience that is anchored in the social and sensitive subjectivity. The enable the audience to reflect on an array of issues that are far from limited to the pandemic.

Keywords: Participatory art, Zoom Theatre, Criticality, Experience, Imagination. 


\title{
Issues of Participatory Digital Theatre. Reflections on Three Forms Developed during the Pandemic
}

\author{
Eliane Beaufils \\ elianebeaufils@aol.com
}

During the COVID-19 pandemic, theatre discovered video conferencing as a performance space for its own purpose. Performances distributed on digital channels however, generally suffer from the competition of other media, not to mention the absence of physical presence which contributes to a lesser affectation of the spectators. One realizes in the absence of co-presence how much it is pegged to reciprocal affectation. Numerous studies attest that digital images and information affect the audience less than physically present people or environments would ${ }^{1}$. Since the effectiveness of a performance broadcast on the Internet is therefore lesser, artists have decided to exploit the format of video-conferencing and transform the theatre into a meeting place. This is not otherwise surprising since the theatre can be defined as a social place where men and women gather and experience what brings them together. It is often criticized for being a place where spectators just meet people with affinities, or it is sublimated as a laboratory for the collective. But the choice of interactivity by videoconference call could appear in the first place as a small compensation for the lack of the co-presence. This article would therefore like to consider the aesthetic, intersubjective and symbolic stakes of these theatricalities.

These issues will evidently be considered with the pandemic as a backdrop. Several hiatuses could play on the apprehension of the screens. The social isolation that lockdowns have produced has notably gone hand in hand with an increase in encounters

\footnotetext{
${ }^{1}$ Two duly analysed cases attest to this: decisions made by computer are much less empathetic and much more calculating in case of danger than reactions deployed in a shared space-time, and images of nature bring less comfort than contact with nature itself. Cfr. respectively D. Eaglemann, Incognito: The secret Lives of the Brain, Canongate Books, Edinburgh 2012 and M.-X. Truong, Nature réelle et nature virtuelle. La réactivation artificielle du lien perdu, in C. Fleury, A-C. Prévot (ed.), Le souci de la nature, CNRS Éditions, Paris 2017, pp. 207-218.
} 
on professional and private platforms. So what distinguishes Zoom or Telegram theatres from meeting spaces or private appointments? And to what extent does theatre benefit from these digital configurations? To answer these questions, I will analyze three different participatory apparatus. I hypothesize that these modes of participation each emphasize a privileged regime of participation and promote specific aesthetic effects. These effects are combined with socio-political effects, where we cannot simply equate participation with democracy. The shows are indeed anchored in atrophied public spaces, which suffer not only from the rarer and more virtual contacts, but also from the obsessive inflation of the information dedicated to the virus. Nevertheless, the interest of these theatrical laboratories may not be limited to a creative response in times of crisis.

\section{The Fictional Foundations of the Apparatus}

The apparatus are all based on fiction mixed with non-fiction, the non-fictional dimension resting primarily on the response of the spectators here and now. However, the fictions take very different forms due to the different use of acting and of fictionalization from spectators.

Familiodrom is a show presented by the Interrobang collective on December 8-9, $2020^{2}$. The spectators first meet the main actor on Zoom, all seeing each other, then the actor starts a story. It is about a little Emilia, who confronts her parents with delicate choices: will she be breastfed by her mother? Should she be given a bottle when she asks for it or should she be fed at set times? The infant is "your" daughter. The spectators thus enter into the fiction as parents of the child. They are also invited to make a decision on another platform. On this site, opened in parallel to the Zoom space, they vote live on the method of breastfeeding to be adopted; then they vote on the hours of breastfeeding. The actor modulates the story of Emilia's early childhood according to the spectators' answers, which appear as graphs. As the show progresses, the spectators will accompany the baby's growth and will be confronted with questions about how she should be raised: should we consider that the three year old child challenges her parents during her defiance phase or does she manifest her autonomy stage? Should we send her

\footnotetext{
2 Interrobang, Familiodrom, December 8-9th 2020, Sophiensäle, Berlin, on-line (https://sophiensaele.com/de/archiv/stueck/interrobang-livestream-familiodrom).
} 
to a public school or a private institution? If private, is it important to differentiate between Waldorf schools, multilingual schools or denominational schools? The vote on the first question will therefore only be taken after more precise considerations and a first vote on private education. Afterwards, the child, now a teenager, is confronted with a different set of questions: how to introduce questions about sexuality, how to react to the new, very punk friend with whom she spends hours in her room, should she be allowed to become an influencer?

The story shows that educational issues go directly hand in hand with reflections on family relationships and with the self-reflection of the parent-spectators. Indeed, the spectators are forced to reflect on their expectations, their modes of subjectivation, their desires projected onto the children, and their power. As the narrator of Emilia's story is sometimes an actor, sometimes an actress, this contributes to generalize the discourses and questions. Throughout the show, the spectators can also add to the discussion: they comment for example on a question by finding that it comes too late («the problem should have been asked well before!») or they express their astonishment in front of the opinion of the majority. At the end of the show, they can discuss together, as they wish. They thus have the possibility of intervening in three different ways during the show.

The second show is not based on a predefined scenario. Die Serienjunkies. Unheimlich online ${ }^{3}$ refers to the addiction to series developed during periods of lockdown, and to the appetite for mystery, detective or gore stories. The spectators find themselves once again in a Zoom space. Wh«en I attended, there were about twenty of us and all our faces appeared on the screen. The actors are ostentatiously made up and wearing big black glasses. These caricatures of characters from crime TV series come back in a tone that is both relaxed and serious about the narrowness that often manifests itself when one is at home for long weeks and sees almost no one. The home becomes an even more strategic and versatile place than usual since it includes work, leisure and rest areas. A spectator is asked to show the room in which she or he is in. In fact, after having stared at the spectators, the actors choose a person and ask them some nonintrusive questions: about where they live, the use of the room they are in, the neighbors or the surroundings. The interpellated spectator is invited to walk around the room with her computer to give a 360-degree view. The actors then surprise the spectators by

\footnotetext{
${ }^{3}$ Jacob Banigan, Beatrix Brunschko and Lorenz Kabas, Die Serienjunkies. Unheimlich online, Theater am Bahnhof, premiered on November 29th 2020.
} 
displaying on the screen (shared this time) an image captured during the 'show room'. Then they start to tell a bizarre story that emerges between these walls.

The protagonist of the story is not the actual interviewed spectator, but a close person or an avatar who takes on certain traits: like Jacob instead of Jacqueline, later on, the questioned student's carpenter mother and the father of the interrogated engineer. Mysterious noises lead the protagonist to all sorts of reactions. He is forced to go to his neighbor's house, the fiction would take him out of the usual framework of life in many ways. The story ends after about ten or fifteen minutes, and then another member of the audience is called upon. Over the course of the session, the audience experiences three somewhat distressing fictions rooted in the various interiors, giving the impression of opening up parallel worlds.

The third apparatus is not a performance per se, even if it appeals to the capacities of representation of each spectator and is based on various documents. Homecoming takes place on Telegram ${ }^{4}$. After a contact and registration phase during the application, each spectator receives an envelope by post. We are invited to do a test before the performance, which lasts about an hour. Spectators use the sheets received by mail and an Internet platform to answer directly. The questions and instructions seem a bit homemade; they seem to want to measure the psychological state of the spectator during this pandemic. At the beginning of the performance, no question is related to the test though. The spectators find themselves in a group of four people who are supposed to have gone to high school together. They all enter a fictional space of mutual fictionalization.

Supposedly, the reality of the pandemic has made them reconnect. One of the women would have crossed paths with Raphael, who seemed to have a fierce personality. The group then contacted the young man, whose telephone number they found. But Raphael refuses any interaction. They all start looking for information about him and come across his confinement blog. At first, the blog seems to be lively, the young man has posted yoga exercises, crafts and cooking recipes. As time goes by, his decision to respect the strictest possible isolation turns out to have disturbing psychological effects that can be detected on the blog: aggressive or defensive texts or recordings of words multiply. The group recalls the test they carried out and tries to recover Raphael's data

\footnotetext{
${ }^{4}$ Machina Ex, Homecoming, October $1{ }^{\text {st }}$ 2020, Forum Freies Theater Düsseldorf, on-line.
} 
during a more complex investigation. The participants manage to get into the site of the socio-medical company responsible for the test, and they can consult the test results of all the participants present. Raphael's test results are extremely worrying; the young man gives all the signs of depression. The players mobilize to bring him the results in person and offer him help, despite Raphael's refusal to open the door. Once contact is made, it seems that the delivery of the mail and the concern of his friends may work in favor of the young man's awareness. After the game is over, players are invited to meet in a chat room with members of their group and other groups.

Looking back at the various narratives shows the importance of the fictional dimension. The apparatus propose dramas very much anchored in the new normal caused by the pandemic. However, these are hardly acted out, they are more told or woven together with the audience. As a result, they delegate a great deal of imagination to the spectators, which is undoubtedly the first and principal way of calling on their participation. The fictional engagement is however of a very different nature from one show to the other, which is due in particular to the various other modes of spectatorial solicitation.

\section{Three Aesthetic Regimes of the Theatrical Participation}

Indeed, the apparatus are anchored in very different social and aesthetic frameworks: Unheimlich is primarily rooted in the concrete and visible habitat of the spectators, so that it develops above all a sensitive imagination in them. Familiodrom creates a scene of education and becomes a permanent space of debate. Homecoming deals with the psychological and social situations of the pandemic. However, the apparatus is less about debates than about actions, stirring up a practical reflection hic et nunc. Thus, the shows call on the spectators to develop respectively the sensitive immersion, the engagement in socio-political debates and the investment in the living together. In a way, they refer to three important theatrical dimensions and potentialities.

Unheimlich seems to be the simplest theatre device to grasp. It engages places and people, all visible at first on Zoom. When a spectator is questioned, the encounter becomes sensitive, even neuromimetic if he or she turns on a lamp, manipulates his/her computer, or takes a few steps in the room. The common activity is then imagination, a minimal form of co-creation, except that the common space of "as if" is particularly 
deliberate: not only do rituals of gongs make the passage to fabulation ostensible, but when the two actors fade away at the moment when the hour of imagination rings, the whole audience enters a theatre of active fabulation. Only the captured image showing a portion of the house is displayed on the shared screen. The co-presence is almost sensory, as it is based on the vision of the room, on the description of the noises, the modulations of light and voices. There is a creation of an atmosphere, an atmosphere at a distance ${ }^{5}$. This atmosphere differs from that of a film because it is suspended to the listening and to the present creation. The atmosphere is doubled by an ambiance (Stimmung $^{6}$ ) associated to bodily feelings, to mystery, detour of familiar signs, the opening of an unsuspected space and the invention of often surreal actions (meeting with the first owner of the mill whose four hundred year old portrait appears on the facade, path in the death). The spectators are projected into a narrated universe, similar to a novel world, and like readers abandoning themselves to their reading in a bubble that belongs only to them, their imagination is also corporeal, their reactions nourished by physical micro-reactions ${ }^{7}$. Finally, such a narration also mobilizes what Fritz Breithaupt calls cultures of empathy ${ }^{8}$. Indeed, the more coherent the fictions are, the more they allow the readers/viewers to project themselves. For empathy is based on cultures of thought, of causality, of habitus, all of which are mobilized by the storytellers.

These different atmospheric, somatic, empathic dynamics are all tendentially immersive. They also have repercussions on the apprehension of one's own environment. The fact that one can invent actions here and now, inside one's home, means in a way that each one can «push the walls» of his habitat. The spectators do not only share, as in a performance, a singular situation, all the more singular because it is specifically dedicated to them. But they share the experience of possibility. The performance possibly liberates places, identities, futures from their assignments: it is

\footnotetext{
${ }^{5}$ See G. Böhme, Atmosphere as the Fundamental Concept of a New Aesthetics in "Thesis Eleven" 36, pp.113-126.

${ }^{6}$ The Stimmung is an ambiance felt by the body, it is an atmosphere with an affective tonality. See H. Schmitz, Atmospheric Spaces/ Espaces atmosphériques, in "Ambiances, International Journal of Sensory Environment, Architecture and Urban Space", transl. by Margret Vince, 2016, https://journals.openedition.org/ambiances/711 (14/05/2021).

${ }^{7}$ Concerning somatic reactions by readers, I refer to the works of Pierre-Louis Patoine, for instance Representation and Immersion. The Embodied Meaning of Literaturein "Gestalt Theory. An International Multidisciplinary Journal", 41/2, pp. 201-216, https://content.sciendo.com/view/journals/gth/41/2/articlep201.xml?rskey=ucUD9a\&result $=9$. $(14 / 05 / 2021)$.

${ }^{8}$ F. Breithaupt, Kulturen der Empathie, Suhrkamp, Frankfurt 2009.
} 
thus liberating of confined horizons. Or, to express it in Deleuzian terms, all the participants share a potentia, an active and generative power ${ }^{9}$. This power is perhaps all the more activated as each one is aware of the making of the tale. To close off the mental theatre by the awareness that we are witnessing an improvised narration could play against the setting up of the mental universe. But seeing the storytellers operate, it is easier to imagine how to operate in turn.

As for the Familiodrom show, it seems to be able to arouse an even more accentuated but also more ideological potentia. The imaginative power is almost equally distributed between spectators and actors, since the story of Emilia evolves according to the votes of the public. This power is moreover directly related to our constitution of subject. Of ideological subject first, since education puts in play values, modes of recognition, projections of oneself. In short, it calls upon subjectivation schemes in the spectators themselves, who identify with the role of parent and with values. And it also calls upon the spectators to recognize themselves as holders of both individual and collective power over the young people who are supposed to subjectify themselves in this or that way. Moreover, each spectator is a subject of democratic debate who participates in a vote and makes his voice heard. The space of the theatre unfolds as a democratic apparatus, but also as a space of common thought. One could qualify it as arch-writing of the education, on the bottom of which all the differances unfold (Derrida). Or this place could be compared to a social chôra according to the meaning of Chantal Jacquet: «the chôra must be thought of as a receptacle susceptible to receive all the forms precisely because it does not have any» ${ }^{10}$. The theatre is built in any case on the background of a space of collective ideas, gathering the movements of ideas common to a community without it being possible to be apprehended as the sum of singular opinions. But the vote forces them to crystallize their positions and not to remain undetermined. The different answers are recorded as in a poll and only the cumulative results are displayed in the form of graphs. These graphs draw the landscape of convictions and a first matrix of the chôra. The ensuing narration is intended to be

\footnotetext{
${ }^{9}$ The difference between power and pouvoir/potentia and potestas is evoked during the interview on "J for Joy" in Gilles Deleuze's L'Abécédaire. While Deleuze refers to "pouvoir" as a rather sad, castrating emotion that affects the "power" of others, he associates "power" with positive emotions, which lead us to deploy our capacities.

${ }^{10}$ C. Jaquet, Philosophie de l'odorat, PUF, Paris 2010, p. 347. We recall that the chôra presented by Plato in the Timaeus (50 d-e) has given rise to countless interpretations.
} 
coherent with the displayed majority, and thus still reflects a disembodied opinion and not the singular option of the actor. The theatrical apparatus thus reinvents a form of democracy at the same time deliberative and direct.

But it is the imaginative speculation which constitutes the base of this democracy. The political power of each one reveals itself further founded on various capacities which cannot be reduced to strict rationality. The people must converge that which supports their constitution of subject: ideological expectations, schemes of intersubjective recognition, affective impulses and imaginative capacities. Moreover, personal reactions are put into perspective by those of others, enlightened by the vast socio-ideological environment that surrounds each one. The space of the theatre allows for the mobilization and reflection of what constitutes each spectator subject. Empowerment through theatre is again based on a form of cleavage of reflection and perception.

Homecoming requires a regular, even constant participation of the spectators, who all become participants. Everyone becomes a co-actor in a double sense: they become a character aiming to "liberate" Raphael, and an actor of the game. The so-called "gametheatre" represents from this point of view a special example because it is hardly possible for the audience members to remain in the background, in a position of potential participants. The investment of the spectators is necessary for the game to take place. As in the other apparatus, however, it should be noted that the spectators are never summoned to respond to solicitations, nor to break their anonymity. But the investment is nonetheless more important: it is temporal (the test and the game last four hours in total), rational and subjective. As in Familiodrom, the apparatus gives rise to speculation on behaviors, which goes hand in hand with the future of the citizen subject: the performance is potentially transformative. Guessing the best ways to reach an end is also playful.

However, transformation through play is far from being solely gratifying. Indeed, the game does not only solicit players as ideological and reflexive subjects, reflecting on the social-psychological help that can or should be given in times of pandemic. It asks everyone to invest in the test and the reactions to others. It, therefore, affects the individual that one is, who may not react in the best way, or who is sent back to his own distress. Is it to compensate for this potentially disturbing investment? The game is also 
the apparatus that most guides the participants' reactions. For they must often find precise clues, their possibilities are limited. Only interaction between players are likely to give an individual twist to cooperation (- did you get the message? - wow, this code is good! - how did you get into the algorithm?). By putting one's own reactions and reflections into perspective, the game is finally endowed with a critical dimension in the Kantian or Brechtian sense: the reflection on individual behaviors and on collective structures that have to do with care is combined with self-reflection.

\section{Less Democratic than Counter-Political Forms of Participations}

The various apparatus set up a mental theatre anchored in the everyday, and which deals with cardinal socio-political issues in Familiodrom and Homecoming. This theatre does not only engage the imagination or even the subjects that we are, but it becomes a space of encounter and co-creation. It thus responds to the favorable preconceptions nourished towards participatory art, which, by developing our capacities, would contribute more or less directly to democratic empowerment. This is the reason why the collaborative and co-creative dimension of devised theatre created with inhabitants constitutes the determining criterion for Estelle Zhong ${ }^{11}$. But it should be stressed once again that the skills and availability deployed in the context of a game are not equivalent to those required for democratic participation. The freedom of thought and the frameworks for action are not equivalent. Moreover, a comparative study of the three performances shows that the performance that apparently makes the least demands on the audience, Unheimlich, may not be the one that affects them the least. Gametheatre is the most collaborative, but it is also the one that frames or manipulates the spectators' actions the most. It is therefore less the quantity than the quality of participation that matters. Moreover, these theatres are the places of argued debates only at the margin: the singularities confront each other only in metacommunications, chats, without developing argumentation strictly speaking. These apparatus are even less the place of decisions that weigh on the course of our lives. In this sense, they are not a substitute for political processes ${ }^{12}$.

\footnotetext{
${ }^{11}$ E. Zhong, La communauté de singularités : réinventer le commun dans l'art participatif britannique (1997-2015), PhD December 4th 2015, at the Institut d'Études Politiques, Paris.

${ }_{12}$ This is the main limitation that philosopher Juliane Rebentisch sees in participatory art. Cf. J. Rebentisch, Forms of Participation in Art, in "Qui Parle", 23/2, 2015, pp. 29-54.
} 
Rather than reverting to an extra-artistic democratic yardstick, I would like to emphasize the potential capacity, or "potentia-lizing abilities" of these apparatus. By calling on the spectators to develop theatres in their heads, they call, as we said, on their cognitive, ideological, and perceptual capacities. But these are micro-political in more than one sense.

Let us underline first of all that the representations rely very little on images. Homecoming, presented on Telegram, uses them regularly, but Unheimlich only uses a screen capture per narration, while Familiodrom only projects the heads of the actors or the sentences on the basis of which one votes. Deprived of an overview and images, the spectators have to actively construct a mental scene, as in reading. This scene also corresponds in Homecoming and Familiodrom to a debate scene. Such a connection is not insignificant. When talking about the theatre as a place for critical discussion, the researcher Nikolaus Müller-Schöll refers to a Derrida lecture at the EHESS, dealing with the death penalty ${ }^{13}$. Derrida begins to speak to his students by evoking an individual who comes knocking at his door. He stages himself as someone who will be questioned at dawn, confronted with a commentary on the death penalty. The beginning of the seminar is thus preceded by a beginning and an answer to a question, in a way by an end. It shows above all that every question is preceded by a scene, a theatre of the question. If the reflection of the object is inscribed in a theatre, it is impossible to set aside this theatre. In the case of an object which cannot be regarded unanimously, such as the death penalty (or education, or care politics), all the participants of a debate are inscribed in this theatre which becomes the preliminary and common condition of thought. This makes the philosopher aware of the precession of the scene of the controversy, which exists even before one mentally enters its enclosure and takes part in the dialogue. Any debate is in truth the matter of a pre-existing scene, already drawn in what composes the social, the language, and this scene emerges when one comes to discuss. Multiple associations, images, sketches, also accompany our discussions like so many composite scenes. The mental representation is thus composed of scenes.

\footnotetext{
13 N. Müller-Schöll, conference at Tanzquartier Wien, December 2016, https://mediathek.tqw.at/tanzquartier-wien-onlinearchiv?tx tqwmediathek pi $1 \% 5 \mathrm{Baction} \% 5 \mathrm{D}=$ detail\&tx tqwmediathek pi1\%5Bcontroller $\% 5 \mathrm{D}=\mathrm{Video} \& \mathrm{t}$ $\mathrm{x}$ tqwmediathek pi1\%5Bvideo\%5D=716\&cHash=884f543410b4ac95c11e095ef1e1d71a (14/04/2021).
} 
The computer screen and the videoconference spaces send the spectators back to these scenes. In the same way as the stage, they constitute a threshold, they open onto these other scenes. An aesthetic conscience is born in the passage of the threshold, in the conscience of this rift and this scenic superposition. As on the stage, one develops a double glance at the same time incarnated and mental. These complex spaces contribute to the activation of plural registers, as much cognitive as subjective, conceptual as imagined. And this complexity in turn stimulates the urge to listen and react in a cognitive and conscious way (what Waldenfels calls "answer") as well as in an intuitive way (what Waldenfels calls "response") ${ }^{14}$.

The creation of overlapping scenes of thought and reception allows us to constantly put into perspective what happens in the performances. It is not possible to immerse oneself in them, as one does in games or quizzes. Because the game or the show puts forward a socio-political debate, it situates the spectators in relation to this debate. Secondly, our position as spectators and actors is related to the position of others and to the debate. That is why the gametheatre cannot be reduced to a game, it is a game within an arena or an amphitheatre in the Polis. It is a game in which we often watch ourselves play more than we play. In this respect, the framing of the game is not so troublesome.

In the context of an increasing number of videoconference meetings, such a theatrical encounter constitutes a break that is even more gratifying as it is perhaps unexpected: one hardly expects the Zoom device to break so far from Zoom habits. It opens up several stage spaces and several meeting spaces, which increases the quality of attention.

The potential breaks with current uses appear even more probable if we take into account the abusive recourse to videoconferences and recordings during lockdowns. In her lecture New narratives of care, Claire Marin also returned to the problems of attention linked to frequent screen $u^{15}{ }^{15}$. On the one hand, the mosaics of videoconferencing, on Zoom, for example, contribute to fragmenting and scattering our attention. On the other hand, they contribute to the desacralization of authority, whether

\footnotetext{
${ }^{14}$ J. Roselt, Phänomenologie des Theaters, Wilhelm Fink, Stuttgart, 2008, p. 175.

${ }^{15}$ C. Marin, Les nouveaux récits du soin (New narratives of care), talk at the Institut Catholique de Paris, May 10 2021, on-line.
} 
it is that of the doctor or the teacher. Finally, they contribute in spite of themselves to reduce "what happens in video" to a spectacle.

Yet, the three theatrical apparatus disregard these various points. The fragmentation of the screen is reduced to a single plane during most of the narrations, which favors concentration. Since much of the "show" is returned to one's mental theatre without being illustrated, it cannot be spectacularized and escapes the circus of media images. The show appeals to the body, to the imagination, to the knowledge of the spectators, so that the frame exerts less violence, at least less constraint. This "violence of the assignment of the frame" is also defused by the playful dimensions of the apparatus, not to mention the fact that they allow for the development of responsiveness in a creative way: each person is called upon to give answers that do not precede him or her, that go beyond the answers that are pre-inscribed in their knowledge.

The experience of reception thus contributes to the future of each spectator; it is capable of being anchored in the memory, if not even of being transformative. Finally, as Claire Marin also reminds us, what marks our encounters is often what precedes or exceeds them: what happens in the margins, interpersonal encounters in the corridors, in the cafeteria, etc. Now, the various theatrical apparatus integrate a sort of «parergonal space» ${ }^{16}$ : one can exchange in chats, share one's spontaneous reactions, move from the central screen to the room of discussion. This reactivates the attention, and contributes to personalize the address.

The various theatrical apparatus studied constitute interactive spaces of encounter and reflection, which, through various means, combine reflection on strategic social realities with the creation of theatrical sociabilities. Both are particularly welcome in times of isolation, deficient of interaction. But the interest of the apparatus is far from being reduced to a therapeutic dressing of our subjectivities in times of COVID-19, which would compensate for the loss of embodied encounters in the rightly called living arts.

\footnotetext{
${ }^{16}$ We recall that Derrida distinguished the parergon from the ergon: the parergon can be presented cavalierly as that which surrounds the work, the fable, and decisively influences its perception or determines its access. It is a framework, a milieu, and this definition is apt to apply to Zoom or Telegram. One can refer to the text of J. Derrida, Plato's Pharmacy, in B. Johnson (ed.), Dissemination, University of Chicago Press, 1981, pp. 61-171.
} 
The contemporary lives are matrixed by the virtualization, they are more and more subjected to the devices, which contribute paradoxically to empty these of sense, or at least of weight. Here the theatres manage to play with the devices, they "profane" their uses according to the well-known expression of Giorgio Agamben: they restore the means to the use of the common ${ }^{17}$. This profanation is the least sensitive in the gametheatre and thus, the apparatus requires a particularly thorough and versatile participation so that responsiveness remains a bit creative and personal.

The three examples refer to movements that the article is far from elucidating. In the vein of the performances which call upon the imagination and the somatic investment of the spectators, one could also evoke Draw my Breath by Antonia Baehr and Jule Flierl, presented in April 2021 ${ }^{18}$. The latter does not resort to somatic immersion in an environment but to a strong bodily participation where the spectators listen to incongruous voices reacting to texts and images, before they too start inventing forms of vocal expression in reaction to drawings. Other performances create spaces of discussion, by resorting to voting devices and habitually renewed interventions models, such as Under Pressure by the collective Henrike Iglesias ${ }^{19}$. However, the spectators vote with their thumbs and not with voting software, which changes the relationship of the voters to each other and the actors. The three tendencies are thus found in new shows but each time they may be declined in a singular and subjectivizing device and give place to experiences that can be from multiple points of view memorable.

\footnotetext{
${ }^{17}$ G. Agamben, What is an Apparatus? And other Essays, Stanford University Press, Stanford 2009.

${ }^{18}$ A. Baehr, J. Flierl, Draw my Breath, April 10-11 ${ }^{\text {th }} 2021$, HAU Berlin.

${ }^{19}$ H. Iglesias, Under Pressure, March 24-26th 2021, Sophiensäle Berlin.
} 